\title{
El Martin Fierro en Borges y Martínez Estrada
}

Es imposible leer hoy el Martin Fierro como fue leído en 1873. También es inútil. Porque toda obra grande está hecha no sólo del texto que fue escrito y publicado en tal o cual fecha sino de los textos superpuestos por algunos lectores privilegiados: textos variados y tan válidos como el original, si es que existe un "original". Por, eso, en este año del centenario, me ha parecido mejor volver al poema de Hernández por el camino, tal vez laberíntico, de dos lecturas famosas, hechas en este siglo, dos lecturas que ya son (para nosotros, al menos) prácticamente inseparables del texto del poema. Me refiero a la múltiple lectura de Borges en varios ensayos, un librito de crítica y algunos relatos, y a la enciclopédica lectura de Martínez Estrada en los dos volúmenes de Muerte y transfiguración de "Martin Fierro".

Inútil aclarat que el enfoque fragmentario de Borges y el totalizador de Martínez Estrada poco tienen de común en apariencia. En tanto que Borges elabora a lo largo de unos treinta años, una visión crítica del poema (matizada en el detalle pero esencialmente la misma), Martínez Estrada despliega en un libro escrito continuadamente un análisis exhaustivo no sólo de la obra sino de su contexto histórico, social, político, económico, cultural, literario. Pocas cosas quedan por escudriñar a Martínez Estrada; muy pocas son objeto de la constante atención de Borges. Y sin embargo, la diferencia de enfoque, la oposición de proyectos, el contraste de las dimensiones (Borges concentra lo principal en un librito de 77 páginas de cuerpo grande; Martínez Estrada necesita de dos tomos de 393 y 520 páginas respectivamente); todo lo que separa a uno del otro, no destruye una unidad básica de la actividad crítica. Tanto Borges como Martínez Estrada aportan a sus respectivas lecturas no sólo una visión enriquecedora de la realidad argentina y una pasión nacional 
(explícita en Martínez Estrada, disimulada por la ironía en Borges) sino que aportan una imaginación crítica, una capacidad de traspasar las capas de estuco acumuladas sobre el texto por la crítica anodina para llegar a la interlínea, para revelar la intertextualidad, para descubrir el palimpsesto. Leer el Martín Fierro que sus lecturas re-escriben es leer una obra infinitamente superior a la que piadosas lecturas conmemorativas nos tienen acostumbrados.

Por eso, no es arbitrario reunir en esta doble lectura la ambición enciclopédica de Martínez Estrada y el miniaturismo borgiano; la vasta persecución de connotaciones que, en definitiva, define el sistema herme. néutico de Martínez Estrada, y el fragmentarismo de brillantes intuiciones (cortes tajantes en la textura del poema) que constituye el método de Borges. Ambas lecturas cubren a su manera el texto, lo re-escriben, lo descodifican. En el caso de Borges, esa descodificación se extiende hasta la parodia: dos episodios del Martín Fierro habrán de servir de base a dos de sus relatos. Pero la parodia (ya se sabe) es una de las formas más eficaces de la crítica literaria, como lo han demostrado Cervantes y Cabrera Infante, para no citar sino a dos maestros.

Una última observación preliminar: elegir a Borges y a Martínez Estrada no significa ignorar tantas otras lecturas válidas del Martín Fierro, desde las que hace el propio Hetnández en algunos textos autocríticos, hasta las de Pagés Larraya y Amaro Villanueva, pasando naturalmente por las de Eduardo Gutiérrez (responsable del enfoque matrero del gaucho), de Lugones (que funda el mito nacional del "gaucho"), de Güiraldes (¿no es Don Segundo acaso el último avatar, la sombra, de Martín Fierro?), o las de Julio Mafud. Habría que escribir un trabajo sobre estos y otros lectores del poema: en ellos, como en Borges y Martínez Estrada, el texto sigue re-escribiéndose.

El mismo Borges ha contado en qué curiosas circunstancias leyó por primera vez el Martin Fierro: tuvo que comprarlo a escondidas porque en su casa el libro estaba prohibido. Su autor, por ser federal, era enemigo de los Borges y los Acevedo. Para Doña Leonor, aquél era un libro sólo digno de maleantes o gente ignorantes. Además, la imagen del gaucho que presentaba era falsa. Por eso, Georgie debió leer el libro clandestinamente, porque para su familia era un libro políticamente pornográfico.

Al contar la reacción de Madre en su "Autobiographical Essay" (en la edición norteamericana de The Aleph, 1970), Borges no se toma el 
trabajo de aclarar que ella estaba equivocada, que Hernández habia denunciado reiteradamente a Rosas en sus escritos políticos. Pero ya en su librito sobre El "Martin Fierro", de 1953, Borges había reconocido que Hernández no era rosista; apoyado en una cita de Pagés Lartaya, afirma entonces: "era federal, pero no rosista".

Esta rectificación de 1953 no pudo haber afectado la lectura que hace Borges (o mejor dicho: Georgie) hacia la primera década del siglo. Para los Borges y los Acevedo, Hernández era, no podía no ser, rosista. El matiz se les escapaba como se les escaparía a muchos contemporáneos. Las cosas se complicaban aún más por el hecho de ser Hernández pariente de los Pueyrredón que eran enemigos de Rosas. Esto lo hacía más repudiable: era un tránsfuga de la causa unitaria, de la causa de la "gente bien", como lo sería (muchos años más tarde) el Che Guevara.

El libro, además era repudiable por su intención política: era una defensa del gaucho, una reivindicación de sus derechos civiles. El poema no sólo cuenta una aventura y un destino; también propone una lectura de la historia argentina, lectura diametralmente opuesta a la efectuada sobre el cuerpo de la realidad por los Borges y los Acevedo. No hay que olvidar que el abuelo paterno, el coronel Francisco Borges, fue precisamente Comandante de Campaña y como tal habrá tenido que lidiar más de una vez con gauchos (para él) rebeldes y desertores, como Fierro. La abuela paterna, Fanny Haslam, que descubrió a Georgie el mundo imaginario de las letras inglesas antes que se le hubiese revelado el de las hispánicas, también compartió con su marido la vida de campaña. El padre de Borges fue engendrado en esa tierra de fronteras; alli murió, en un combate de las guerras civiles, el abuelo. Era en 1874., cuando Martín Fierro sólo había cumplido un año.

En ese contexto familiar, es comprensible que Georgie tuviera prohibida la lectura del Martín Fierro y que, por eso mismo, lo comprara a escondidas y lo leyera clandestinamente. Hoy parece casi inconcebible que los viejos criollos argentinos hayan tenido una actitud tan negativa frente al gaucho. Pero hay que recordar que antes de 1916 (fecha de El payador, de Lugones) el gaucho no es el símbolo de la nacionalidad argentina; es, más bien, el símbolo de la barbarie que la nueva orgullosa nación quiso no sólo erradicar sino obliterar pos el olvido. En su librito sobre el poema, trazará Borges un cuadro histótico que permite situat mejor su perspectiva de clase frente al poema:

Con la acción de Ayacucho, librada por los ejércitos de Sucre en 1824, se consumó la Independencia de América; medio siglo después, en campos de la provincia de Buenos Aires, la Conquista no 
había tocado aún a su fin. Al mando de Carriel, de Pincén o de Namuncuré, los indios invadían las estancias de los cristianos y robaban la hacienda; más allá de Junín y de Azul, una línea de fortines marcaba la precaria frontera y trataba de contener esas depredaciones. El ejército cumplía entonces una función penal; la tropa se componía, en gran parte, de malhechores o de gauchos arbitrariamente atreados por las partidas policiales. Esta conscripción ilegal, como la ha llamado Lugones, no tenía un término fijo; Hernández escribió el Martín Fierro para denunciar ese régimen. Se propuso evidenciar que esas levas eran la ruina de la gente de campaña. $(M F, 30)$

Aunque la reticencia británica de Borges le impide decirlo es evidente que al dictar esas frases a su colabotadora, Margarita Guerrero, él no pudo no pensar que su abuelo, el coronel Francisco Borges, habria tenido que recibir en su calidad de Comandante de Campaña a muchos gauchos como Fierro y que el poema, escrito para defender a un elemento mal integrado socialmente, o francamente asocial, era un ataque a esa misma clase que había oprimido y destruido al gaucho. Desde este punto de vista, Hernández no sólo había traicionado a los suyos al ser federal; los había vuelto a traicionar al escribir el poema. Era un doble tránsfuga para los Borges y los Acevedo.

El texto de Borges arriba citado contiene una paradoja no explícita. Porque las hazañas de la Independencia de América fueron cumplidas por los mismos gauchos que luego serían confundidos con malhechores en las levas efectuadas medio siglo más tarde de Junín. Aunque tal vez no sea correcto decir que eran los mismos gauchos. Entre el gaucho de la Independencia y el sometido a la leva en la frontera hay no sólo la distancia de medio siglo: hay toda una transformación social y politica. El gaucho ya no es el dueño de la pampa, el jincte invencible: es un paisano sometido a una autoridad arbitraria, enfrentado a un enemigo mucho más diestro (el indio), emasculado por el Estado de su virilidad. Pero esa paradoja está sólo implícita en el texto de Borges y era, seguramente, invisible para su abuelo.

El coronel Borges no sería excepción en su clase: para la gente pudiente de entonces, el gaucho representaba la ralea, la barbarie, las masas armadas que tanto podian servir para una causa justa (la Independencia) como para ponerse al servicio de estancieros bárbaros y ambiciosos (como Rosas y los demás caudillos); masa que al desintegrarse en unidades, perdía toda grandeza. Esta es la visión oficial de la historia argentina de entonces, la que aparece reflejada en otra obra que Georgie sí en- 
contró en la biblioteca de Padre. Es el Facundo, de Sarmiento, cuyo subtítulo, "Civilización y batbarie", recoje la dicotomía sobre la que se edifica la Argentina, la oficial. En este libro, y no en el Mariñn Fierro, encontratá Georgie la visión histórica que lo confirma en su clase y su cultura. En la misma biblioteca paterna están la Historia Argentina, de Vicente Fidel López, y las heroicas biografías de San Martín y Belgrano, por el general Bartolomé Mitre.

Pero lo que me importa subrayar ahora es que a pesar de la prohibi. ción familiar, Georgie adquiere el libro a escondidas y lo lee. Esa lectura habrá de tener inesperadas consecuencias.

Las primeras huellas del Martin Fierro pueden reconocerse en los ensayos críticos que Borges publica en volumen a partir de 1925. Aunque el que recoge (en Inquisiciones, de ese año) no está dedicado al poema sino a Ascasubi, ya puede situarse en esa fecha la preocupación explícita por el tema gauchesco. Al artículo sobre Ascasubi, sigue otro sobre Estanislao del Campo (El tamaño de mi esperanzat, 1926) en que recuerda que el autor "fue amigo de mis mayores". Sólo en 1931, aborda directamente el Martín Fierro, en un trabajo que recoge en Discusión (1932). El largo rodeo es explicable: lentamente decide Borges acercarse en público al libro prohibido. Ascasubi (unitario, anti-rosista) es de los "nuestros", como lo es del Campo, amigo de sus mayores. Pero ya en 1931, Borges siente tal vez que ha cumplido con la piedad filial y puede leer en público el Martín Fierro. El tabú ha sido desafiado, la vieja prohibición ha perdido su efecto.

Esa primera lectura será el origen de una serie de lecturas posteriores (algunas con muy pequeñas variantes) que Borges efectuará en el curso de dos décadas: hay una conferencia en Montevideo (1945), recogida en panfleto en 1950, Aspectos de la literatura gaucbesca; hay el librito compilado con la colaboración de Margarita Guerrero, en 1953; hay el prólogo, redactado en colaboración con Adolfo Bioy Casares, a una antología en dos volúmenes de las obras centrales de la Poesía gauchesca (1955). En ese contexto, la imagen del Martin Fierro en la obra crítica de Borges termina por fijarse en algunos puntos centrales. Su lectura descodifica ciertos elementos, y casi siempre los mismos. Por razones de síntesis se examina aquí sólo el texto más largo.

Conviene advertir, en primer lugar, que el librito fue escrito de encargo para una colección "Esquemas" y que por eso contiene mucho 
material informativo, imprescindible por el carácter pedagógico de la colección pero poco habitual en los trabajos de Borges. Lo más importante no es esa información, que es posible encontrar (mejor, más abundante) en otras obras, sino los toques borgianos de su texto. Ya en el prólogo se advierte:

Hace cuarenta o cincuenta años, los muchachos leían el Martin Fierro como ahora leen a Van Dine o a Emilio Salgari; a veces clandestina y siempre furtiva, esa lectura era un placer y no el cumplimiento de una labor cultural. $(M F, 7)$.

Inútil observar que el "ahora" de Borges es anacrónico: en 1953, los muchachos no leían a Van Dine y a Salgari, sino a William Irish y a Ellery Queen. Lo que importa es que al definir la lectura de Martín Fierro ("clandestina", "furtiva", placentera), Borges está definiendo su primera lectura, la de Georgie.

El librito mismo articula en seis capitulos el estudio del poema: (1) La poesía gauchesca que examina la obra precursora de Hidalgo, Ascasubi, del Campo, y el "olvidado" Lussich, y es un resumen de trabajos anteriores; (2) José Hernández, que da la biografía del poeta y cita opiniones de su restante obta literaria; (3) El gaucho Martín Fierro y (4) La vuelta de Martín Fierro, que estudian las dos partes del poema; (5) Martín Fierro y los críticos, que examina las opiniones más famosas; (6). Juicio general, en que resume su punto de vista y adelanta algunos enfoques válidos. Una Bibliografía selecta completa el librito.

Los cuatro últimos capitulos lo justifican. Allí Borges repasa sintéticamente el poema y acumula felices observaciones de detalle sobre:

(a) La ficción autobiográfica en que se basa el poema y que postula una "extensa payada" llena de "quejas y bravatas del todo ajenas a la mesura tradicional de los payadores" (p. 31);

(b) La ausencia de lo épico en el poema ya que "Hernández quería ejecutar lo que hoy llamaríamos un trabajo antimilitarista y esto lo forzó a escamotear o mitigar lo heroico, para que los tigores padecidos por el protagonista no se contaminaran de gloria" (p. 35);

(c) La presencia de un elemento "sobrenatural" en el poema: "En el Martín Fierro como en el Quijote, ese elemento mágico está dado por la relación del autor con la obra" (p. 45);

(d) El error de extrapolar los consejos del viejo Vizcacha fuera del contexto que da la historia del personaje: "son parte del retrato y no deberían ser otra cosa" (p. 57);

(e) La mise en abîme de una payada (la general de Martín Fierro) 
que incluye otra (la del protagonista con el negro), efecto que Borges vincula a operaciones similares de Hamlet y Las mil y una noches (p. 61);

(f) La circunstancia de que el final del libro sugiere episodios fuera del mismo: "Podemos imaginar una pelea más allá del poema, en la que el moreno venga la muerte de su hermano", dice Borges apuntando hacia un cuento que él escribitá (p. 65);

(g) El error de leer el Martín Fierro como epopeya: "Esa imaginaria necesidad de que Martín Fierra fuera épico, pretendió así comprimir (siquiera de un modo simbólico) la historia secular de la patria con sus generaciones, sus destierros, sus agonías, sus batallas de Chacabuco y de Ituzaingó, en el caso individual de un cuchillero de mil ochocientos setenta" (p. 70);

(h) La mayor cercanía de Martín Fierro al género novelesco: "La epopeya fue una preforma de la novela. Así, descontado el accidente del verso, cabría definir al Martín Fierro como una novela. Esta definición es la única que puede trasmitir puntualmente el orden de placer que nos da y que condice sin escándalo con su fecha, que fue ¿quién no lo sabe? la del siglo novelístico por excelencia: el de Dickens, el de Dostoievski, el de Flaubert" (p. 74);

(i) La ambigüedad final del protagonista, calificado por unos de hombre justo, por otros, de "siciliano vengativo" (la frase es de Macedonio Fernández); Borges acepta la ambigüedad como condición de la naturaleza novelesca de la obra: "La épica requiere la perfección en los caracteres; la novela vive de su imperfección y complejidad" (pp. 74-75);

(j) La identificación del lector con el protagonista que constituye uno de los méritos del libro: "Si no condenamos a Martín Fierro, es porque sabemos que los actos suelen calumniar a los hombres. Alguien puede robar y no ser ladrón, matar y no ser asesino. El pobre Martín Fierro no está en las confusas muertes que obró ni en los excesos de protesta y bravata que entorpecen la crónica de sus desdichas. Está en la entonación y en la respiración de los versos; en la inocencia que rememora modestas y perdidas felicidades y en el coraje que no ignora que el hombre ha nacido para sufrir. Así, me parece, lo sentimos instintivamente los argentinos: Las vicisitudes de Fierro nos importan menos que la persona que las vivió" (pp. 75-76).

La lectura de Borges es sutil. Rectifica muchos lugares comunes de la crítica anterior, como las que lo consideran un poema épico (ver $b, g$ y $h$, sobre todo), o presentan el carácter del protagonista como si fuera monolítico (ver $i$ y $j$, en particular). Pero a esas necesarias rectificaciones, agrega Borges otras perspectivas, muy suyas. Una es el reconoci- 
miento de una "perspectiva abismal", técnica que él utiliza en sus cuentos y que en Martin Fierro le permite advertir la payada dentro de la payada (ver $e$ pero también a y c); lo que da a su lectura el elemento "sobrenatural" y "mágico" tan ausente de otras interpretaciones realistas, y aun pedestres. Otra perspectiva apunta a la vida de la obra fuera de la obra: la posibilidad (esbozada en $f$ ) de prolongar imaginariamente los episodios de Hernández. Esa posibilidad no fue descuidada por Borges, el narrador.

Su lectura del Martin Fierra, como la del Quijote por "Pierre Menard", es idiosincrática. En ningún lado se ve mejor que en los dos cuentos que Borges dedica a "expandir" la acción del poema. Ya en la elección de los episodios se advierte esa manera lateral y hasta oblicua de leer que es característica suya: en el cuerpo abundante del poema Borges sólo elige la historia de Cruz y el enfrentamiento final de Fierro con el payador negro. (Hay otro eco del poema en un tercer cuento, del que hablo luego.) El más famoso desde este punto de vista estrictamente borgiano es "Biografía de Tadeo Isidoro Cruz (1829-1874)". Fue escrito en 1944 y está recogido en El Aleph (1949). A primera vista, el cuento no tiene nada que ver con el personaje del poema. Sólo en las últimas líneas, Borges identifica a su Cruz con el de Hernández. La "biografía" es un minucioso ejercicio de reconstrucción que cubre todo el texto de Hernández pero para poner los énfasis en otro lado, y despistar así al lector. Uno de los recursos que utiliza es la precisión de nombres, lugares y fechas, a empezar con ese Tadeo Isidoro que desplaza la atención del apellido e impide reconocer al personaje. (Hernández sólo lo llama Cruz.) Para distraer más a su lector, Borges utiliza detalles históricos que vienen de su historia familiar: el general Suárez del comienzo del cuento es su bisabuelo materno; el rancho donde trabaja Cruz, pertenece a otro pariente materno, Francisco Xavier Acevedo; el Laprida que lucha contra los indios es también pariente suyo. De esa manera, Borges saca al personaje de Hernández de su contexto novelesco, sin fechas, sin precisiones, sin nombres históricos reconocibles, y lo sitúa en otro contexto biográfico imaginario pero exacto. Sólo al final, cuando los destinos de Fierro y Cruz se juntan, Borges deja de inventar variantes y se limita a resumir a Hernández. Pero en ese momento ya no importa: el lector está a punto de saber quién es Cruz y de dónde viene: de un texto literario y no de la mera realidad. La técnica de Borges es la del relato policial, pero es también la de la parodia. 
En unos comentarios a la traducción norteamericana del cuento, Borges ha contado por qué se sintió attaído por ese episodio del poema: el hecho de que el sargento Cruz abandone su puesto en la partida policial y se ponga de parte de un matrero, le resultó siempre incomprensible. Escribió el cuento para explicarse ese destino. En el cuento, Cruz deja de ser el personaje algo indeciso y débil que presenta Hernández (Martínez Estrada lo calificará aún más duramente) para convertirse en uno de esos prototipos borgianos: un ser cuyo destino consiste en un solo instante verdadero y que vive sólo para esa iluminación. Borges, como era de prever, convierte a Cruz en materia propia.

El otro cuento que deriva del poema es "El fin", que ya estaba anunciado en la página 65 del librito sobre El "Martin Fierro" (ver $f$ ), y que fue escrito también en 1953. (Está en la segunda edición de Fic. ciones, 1956). Como en la biografía de Cruz, sólo en las últimas líneas se sabe que uno de los personajes deriva del poema de Hernández. Es un cuento breve y enfocado desde la perspectiva de un pulpero, Recabarren, que está inmovilizado en un catre por una hemiplejía. Desde allí asiste al desafío de dos hombres y al duelo en que uno (el negro) mata al otro. Es un ajuste de cuentas. Insertado en el contexto del poema, este duelo cierra la payada con que concluye narrativamente la Vuelta. Pero lo cierra a la manera de Borges. Precisamente una maneta que Hernández se había negado a sí mismo. La Vuelta debe terminar con una reconciliación (como la del Quijote con la realidad); esa reconciliación significa que el gaucho Martín Fierro, que el gaucho a secas, acepta el nuevo lugar que le ha destinado la sociedad, acepta la ley y el orden. Insertar el duelo aquí (como hace Borges) es desmentir el poema.

Pero en el contexto de su propia obra, "El fin" dice otra cosa: el duelo es repetición ritual del duelo de Martín Fierro con el hermano del negro, siete años antes. Hay mínimos detalles que los unen: después de matar a Fierro, el negro limpia el cuchillo en el pasto, como había hecho el protagonista después de matar a su hermano. Pero en la repetición ritual se ha deslizado un elemento indiscutiblemente borgiano que las últimas líneas del cuento ilustran:

Limpió el facón ensangrentado en el pasto y volvió a las casas con lentitud, sin mirar para atrás. Cumplida su tarea de justiciero, ahora era nadie. Mejor dicho: era el otro: no tenía destino sobre la tierra y había matado a un hombre. $(F ., 1956$, p. 189)

Había cumplido su destino: ya no era nadie. ¿Cuántas veces estas palabras (estos conceptos) aparecen en los textos de Borges? El personaje de 
Hernández es un personaje limitado pero reconocible; el de Borges, es un prototipo, intercanjeable. La visión de Hernández es, a pesar de toda su melancolía y su tono a veces lacrimógeno, una visión que se detiene de este lado de la realidad; la de Borges, atraviesa la realidad y busca su sentido más allá: en el destino condensado en un solo instante; en la aniquilación de la individualidad; en la magia del texto que desrealiza todo. El Martin Fierro de Hernández se ha convertido en el de Borges.

Queda un tercer cuento en que se pueden encontrar ecos de la lectura de Hernández. Es "El Sur", también de 1953, también recogido en la segunda edición de Ficciones. En el desenlace de este cuento, el protagonista, Juan Dahlmann llega (como en sueños) a una pulpería de la provincia de Buenos Aires, es desafiado por un compadrito y recibe la ambigua ayuda de un viejo gaucho que a él se le figura un arquetipo: "una cifra del Sur (del Sur que era suyo)". A un nivel de lectura, el que está sugerido por el protagonista del cuento, el gaucho trata de ayudar a Dahlmann, arrojándole una daga, así podtá pelear con el compadrito. El gaucho sería como la prolongación, o última decadencia, de Don Segundo Sombra. Pero una segunda lectura permite advertir que la acción del gaucho habrá de contribuir no a su salvación sino a su muerte previsible. Ya su figura no aparece como el prototipo del padrino (sombra) sino como prototipo de un personaje canallesco del Martín Fierro, el viejo Vizcacha. Es precisamente la ambigüedad del personaje en este cuento, la que define finalmente la ambigüedad última de la lectura (la re-escritura) de Borges. Su Martin Fierro, fragmentario, caprichoso, es tan insondable como el original, aunque es definitivamente otro.

A partir de un prólogo a la edición Jackson de Martín Fierro (1938), Martínez Estrada desarrolla durante unos diez años el estudio que habrá de culminar en Muerte y transfiguración de "Martin Fierro" (1948). Paradójicamente, aunque él escribió mucho más y su escritura crítica cubre más completamente el modelo, su lectura es más fácil de sintentizar que la de Borges. Por ser más sistemático, por aparecer organizado en una unidad de discurso, por contener su propia glosa, su vasto libro es más simple. Esto no quiere decir que sea menos complejo. Al contrario. Aquí sólo se examinará un aspecto de esta obra capital. Porque sería posible estudiarla no en el contexto del Martín Fierro sino de la obra ensayística entera de Martínez Estrada. Entonces habría que verla como la pieza central en una exploración de la realidad atgentina que se inicia 
con Radiografía de la Pampa (1933), y que tiene en La Cabeza de Goliat (1940), Sarmiento (1946) y Los invariantes bistóricos en el "Facundo" (1947), sus otros hitos fundamentales. Pero este enfoque excede los límites de este trabajo.

La obra se divine en dos volúmenes: (I) Las figuras; (II) Las perspectivas. En (I) hay tres partes: (1) Las personas, dividida en dos capitulos: (a) La primera persona: el cantor; (b) Los personajes, entre los que se cuenta a Martín Fierro, separando así la "persona" del cantor, de la personalidad del protagonista; (2) La Frontera, estudia en tres capítulos los siguientes temas: (a) El territorio; (b) Los habitantes: La lucha contra el indio; (c) Los habitantes del gaucho; (3) El orbe histórico, que consta de un solo capítulo. En (II) hay siete partes: (1) Morfologia del poema; (2) Las estructuras; (3) Los valores; (4) El "mundo" de Martín Fierro, subdividido en tres capítulos: (a) Los temas; (b) Miscelánea; (c) La vida; (5) El habla del paisano; (6) Lo gauchesco; (7). Las esencias.

Por este mero resumen se advierte la intención totalizadora de Martínez Estrada y su esfuerzo por estructurar un análisis que descubra en definitiva no sólo el entronque de Martín Fierro con una realidad nacional (sobre todo en I, 2, 3; pero también en II, 3, 4, 5, 6 y 7), sino también revele la naturaleza poética de la obra, tarea a la que dedica buena parte del tomo I, y toda una sección del II (la primera). El resultado es un análisis que por un lado participa del múltiple enfoque sociológico-psicoanalítico-existencialista, y por otro explica algunas técnicas aprendidas en la estilística y en la escuela alemana de la crítica morfológica. No hay unidad en el enfoque ni hay un propósito (como el de Goldmann en su libro sobre Pascal y Racine, o como Sartre en el Saint Genet) por reducir la multiplicidad de enfoques a una sola visión. Martínez Estrada se prevalece de la ambigüedad original del texto -que es un panfleto político a la vez que un poema- para pasar del poema a la realidad y viceversa, para saltar de la sociología a la estilística, de la morfología al psicoanálisis existencial.

El resultado es algo abrumador, aunque casi siempre interesante $y$, a ratos, deslumbrante. La inteligencia de Martínez Estrada, su finísima sensibilidad, su imaginación para las palabras, rescatan muchas veces su texto de algunas evitables arideces, del desmedido afán enciclopédico, de la reiteración, la tautología. Libro para ser leído por sí mismo, como una obra autónoma sobre la pampa, los gauchos y un momento decisivo de la nacionalidad argentina, también puede leerse como un estudio del poema: el más ambicioso, el más iluminador. 
No es posible examinar aquí todo lo que descubre Martínez Estrada en su lectura. Me limitaré a señalar algunos de los puntos más interesantes de su análisis. En el primer volumen (I) apunto:

(a) Al analizar la personalidad de Hernández y su rebeldía contra los Pueyrredón, Martínez Estrada revela un aspecto del poema que se le había escapado por completo a la mayoría de sus lectores, y a los Borges en particular: Esta es una obra censurada, en el sentido psicoanalítico del término. "Lo feo que pinta encubre lo más feo que calla. No era lo más malo aquello que describía sino 'lo más malo de lo que la censura patriótico-gentilicia le permitía decir" "(p. 30);

(b) Hay una transferencia del personaje al autor ("Soy un padre al cual ha dado su nombre su hijo", dijo Hernández una vez) que se basa en que lo gauchesco en éste nace de un complejo de inferioridad: et campo es para él una dolorosa experiencia; abrazó el partido de los gauchos "por disgusto, por reacción contra ellos. Es un amor que nace por ambivalencia del odio" (pp. 32-35);

(c) Martín Fierro carece de personalidad humana; sólo la tiene alegórica, ya que es "una imago, un ser producido por una transferencia y por una censura" (p. 46);

(d) Establecida la transferencia, Martínez Estrada indica que el Martín Fierro es el primer poema gauchesco en que el autor "resuelve ceder al protagonista el papel de narrador" (p. 47);

(e) Al empezar a analizar el poema, lo primero que advierte es que el corte entre la Primera y la Segunda Parte (la "Vuelta") no está bien hecho, y que su estructura se resiente por ello (p. 55); también observa que en la Payada culmina el poema y la personalidad del protagonista (p. 57);

(f) La diferencia mayor entre la Primera y la Segunda Parte del poema, está en el cambio que sufre el protagonista: en la Primera lamenta su destino en forma viril; en la Segunda, sus quejas son las de un vencido (p. 71); ese cambio también se traduce en la relación simbólica del autor con el protagonista; "En la Primeta Parte Hernández era Martín Fierro, en la Segunda, Martín Fierro es Hernández" (p. 74);

(g) Cruz le parece el doble simiesco, la caricatura de Fierro (p. 80); su personaje ha sido esbozado cronológicamente antes que el de Fierro, y ocupa el segundo lugar en un desartollo que va de Picardía (el núcleo inicial y canallesco) hasta Fierro, en que se depuran las cualidades negativas más repelentes de ambos (p. 82); 
h) Vizcacha es más honrado que Martín Fierro, ya que al aconsejar la desconfianza, el egoísmo, la prudencia y la doblez no hace sino poner de acuerdo su enseñanza con su experiencia; Fierto, en cambio, no lo hace y sus palabras "suenan a sermón preparado de antemano" (p. 88); por eso, Martínez Estrada califica a Vizcacha de "la creación máxima de todo el Poema, dentro del rigor de veracidad que el autor se había impuesto como norma" (p. 88);

(i) La figura del Hijo Mayor le parece de estatura kafkiana (p. 90);

(i) Distingue entre lo que cuenta Hernández y lo que comenta: lo primero está tomado de la realidad; lo segundo ya es literario: "Siempre es la interpretación lo malo. Hay en Hernández un élan hacia lo legendario, y el acomodo del cantor harapiento en los cánones del héroe, la metamorfosis de un ser real en un ser ideal ya está operada en su Martín Fierro" (p. 256); de ahí que hasta cierto punto, Hernández sea responsable de la posterior canonización y exaltación nacional del protagonista: "una nueva superchería: (...) un ídolo con el que se puede crear toda una liturgia de festejos y de oratoria, pero en el que nadie cree" (p. 258).

El segundo tomo (II) estudia más en detalle el poema. El análisis es tan minucioso, y se reiteran tanto los temas de (I), que resulta imposible esquematizatlo. Me limitaré a subrayar algunos enfoques particularmente penetrantes:

(a) Al discutir el problema del género al que pertenece el poema, y después de apuntar que es "una obra tan desordenada y compleja" (p. 106), cita a Borges (que se inclina por considerarla novela) y concluye: "No es excesivo, pues, suponer un yerro inicial al intentar condicionar el Poema en la tesitura de una elegia, y de ese antagonismo, latente cuando no palmario, resulta un tipo de relato que puede ser - colocado en compañía de las concepciones igualmente híbridas de Kafka, Proust y Joyce" (p. 110);

(b) Subraya el arte de la litote (aunque no usa esta figura) que define la poética de Hernández: "Todo en el Poema está elaborado con suma conciencia artística, con el propósito de extraer mucho provecho de poco" (p. 146);

(c) Hay una contradicción entre el tema de la obra y su tono: "Hernández plantea el destino de una 'clase derrotada' $y$, sin embargo, su obra queda comprendida en las características de las obras tragicómicas. La lectura del poema suscita dos sentimientos contrarios: a lo largo de la lectura, las vidas de los personajes no impresionan por sus desdichas, pero el recorrido, en casi todos los versos, es de tono jocoso" (p. 1.71); esto vincula aún más al poema con el género picaresco, como ya había antes observado Martínez Estrada; 
(d) También subraya el carácter grotesco del poema: "No es una parodia sino una obra grotesca en que la urdimbre es de la más pura calidad dramática, en lo humano, y el botdado de la más hilarante apostura humorística. Hernández no ha eliminado lo cómico en la poesía gauchesca: lo ha llevado al paroxismo, superando los límites de lo épico y lo dramático" (pp. 175.176);

(e) Insiste en la importancia de lo que falta en el poema, las ausencias que dan relieve a lo que hay: "Diría que el fondo del Pocma, lo que lo envuelve, el cielo, el campo, el silencio, la soledad, la muerte, la tristeza, lo que no está contado como tal cosa, aludido, evitado, es lo sublime" (p. 184);

(f) Señala la necesidad de una lectura palimpséstica del texto: "Los ejemplos, los consejos, todo ello coloca en primer término un texto, y la lectura ha de hacerse en el revés de la página, en el otro lado. Acaso un valor inédito provenga de los errores de plan y de composición del Martin Fierro, que le obligan a circunloquios y equívocos, a superposiciones: de ahí un arabesco rico en la simplicidad del dibujo, aquí un trasfondo de palimpsesto en la lectura literal de la letra clara, escolar" (188); y, más adelante, insiste: "El Poema es una escritura jeroglífica; mejor dicho, una criptografía" (196);

(g) Hernández concibe a Martín Fierro no sólo como un tipo humano sino ya como personaje de un poema: "Martín Fierro es considerado como un libro. (...) El modelo era ya para él una obra literaria: lo que copiaba no lo convertía de realidad en poesía, sino que lo tomaba ya así, en su doble significado de cosa y de valor" (p. 237).

Vuelvo a insistir: esta selección de juicios e intuiciones no pretende agotar la infinita abundancia del estudio de Martínez Estrada. Apenas si busca apuntar, con algunas válidas muestras, su variedad, su penetración, su luz.

No sería imposible trazar un paralelo entre estas dos lecturas y mostrar los puntos centrales de sus simpatías y diferencias. Así ambos coinciden en negar, contra la opinión corriente y las lecturas patrióticas, el carácter épico del poema e insisten, por el contrario, en sus vinculaciones con la novela (Borges, $b, g$ y $b$; Martínez Estrada, II, $a, c$ y $d$ ). La matización es más delicada en Martínez Estrada, que destaca por ejemplo mejor el carácter de "obra abierta" (aunque no usa esta expresión, que emplearía Umberto Eco mucho más tarde), de obra grotesca, lo que acentúa 
el parecido con Dickens, ya apuntado por Borges, el que había agregado además los nombres de otros dos maestros del grotesco: Dostoievski, Flaubert (el de Bouvard et Pécucbet, es claro).

También coinciden ambos en subrayar el carácter literario del texto de Hernández que queda establecido por la peculiar relación del autor con la obra (Borges, $c$ ) y la utilización de la mise en abîme para situar una payada dentro de otra (Borges, $e$ ); temas que Martínez Estrada desarrolla, con otro vocabulario pero enfoque similar, al señalar (II, $g$ ) cómo Hernández concibe al protagonista no sólo como un tipo humano sino también como "personaje" de un "poema". Finalmente, aunque sus métodos críticos son tan distintos, vuelven a coincidir en el mérito final, poético, del libro (Borges, $j$; Martínez Estrada, $e$ ).

Esas coincidencias apuntan a una que las subsume: tanto Borges como Martínez Estrada practican una lectura palimpséstica del texto; es decir: una lectura que lee la entrelínea, el envés, que practica la confrontación intertextual. Por eso, las lecturas de ambos resultan armonizadas al final. Esto no quiere decir que cada uno no defina básicamente un territorio que le es propio. Sería inútil buscar en Borges el tipo de análisis psicoanalítico-existencial en que abunda el libro de Martínez Estrada (sobre todo, en $\mathrm{I}, a, b, c, d, \mathrm{y}$ algo de $j$ ). Es conocido el desprecio de Borges por el psicoanálisis, particularmente de tipo freudiano; aunque el enfoque de Jung le parece mejor, lo considera válido sólo como folklore. Por eso, su análisis de las relaciones de Hernández con la obra se detienen en el contexto biográfico-histórico explícito, o sólo apuntan (como en a y c) una relación literaria del autor y el poema. También está ausente del librito de Borges el estudio enciclopédico de la realidad argentina que intenta Martínez Estrada y que el subtítulo de su obra ilustra precisamente: "Ensayo de interpretación de la vida argentina".

Esto no quiere decir que no haya una notable coincidencia en muchos de los juicios sobre el pasado argentino. Pero el examen del tema escapa a este trabajo. Ahora preferiría indicar otro vínculo entre las lecturas de Borges y Martínez Estrada: por ser coetáneas, es posible trazar algunas líneas constantes que las unen. En primer Jugar, Martínez Estrada cita reiteradamente los trabajos de Borges en el texto de su obra (I, pp. 66, $79-80 ;$ II $, 11,49,107,147,222,350)$. Casi todas las veces, lo hace para subrayar una coincidencia. Es cierto que en la Bibliografía los estudios de Borges están omitidos, pero esto puede deberse a una descuidada corrección de las pruebas. En el Indice de obras citadas reaparece Borges. aunque también hay aquí algunas erratas y omisiones menores. Lo que importa no es esta minucia sino que el propio Martínez Estrada subraye 
varias veces las coincidencias y acuerdos. Por su parte, Borges resume con estas palabras su juicio sobre el libro de su colega:

Trátase menos de una interpretación de los textos que de una recreación; en sus páginas, un gran poeta que tiene la experiencia de Melville, de Kafka y de los rusos, vuelve a soñar, enriqueciéndolo de sombra y de vértigo, el sueño primario de Hernández. Muerte y transfiguración de Martin Fierro inaugura un nuevo estilo de crítica del poema gauchesco. Las futuras generaciones hablarán del Cruz, o del Picardía, de Martínez Estrada, como ahora hablamos del Farinata de De Sanctis o del Hamlet de Coleridge. $(M F, 72-73)$.

Por este juicio, Borges no sólo celebra el libro de Martínez Estrada sino que, tácitamente, subraya el vínculo profundo con su propia lectura, la de los cuontos tanto como las de los ensayos: en Martínez Estrada, como en Borges, el Martin Fierro vuelve a ser escrito. La lectura crítica se transforma así en escritura.

EMIr Rodríguez MONEGAL

Yale University.

Nota bibliografica:

He utilizado principalmente los siguientes textos de Borges: (1) El "Martin Fierro", escrito en colaboración con Margarita Guerreto (Buenos Aires, Editorial Columba, 1953); (2) Ficciones (Buenos Aires, Emecé Editores, 1956); (3) El Aleph (Buenos Aires, Editorial Losada, 1949); (4) The Aleph and Other Stories (New York, E. P. Dutton, 1970). Para Martínez Estrada, utilicé Muerte y transfiguración de "Martin Fie. rro" (México, Fondo de Cultura Económica, 1948, dos volúmenes). Cuando Martinez Estrada cita a Borges lo hace por Discusión (Buenos Aires, Gleizer Editor, 1932), o por la edición primera de El Aleph (Ver. no. 3).-E.R.M. 